\title{
Potencial inovativo da indústria nas regiões brasileiras
}

Ednaldo Moreno Góis Sobrinho*

Carlos Roberto Azzoni**

Recebido: 29/06/2015 Versão revisada (entregue): 24/12/2015 Aprovado 04/02/2016

\section{RESUMO}

Este trabalho apresenta um novo índice para medir, em níveis geográficos desagregados, o potencial inovativo das regiōes no setor industrial. $O$ índice considera conjuntamente o nível tecnológico dos setores, as ocupações associadas a P\&D e as habilidades, perícias, conhecimentos e outras características dos trabalhadores. Os índices calculados para regiōes, estados e municípios, no período 2003-2012, revelam que o Sul e Sudeste ainda têm a indústria potencialmente mais inovativa. A evolução dos índices mostra que áreas tradicionais registraram crescimento inferior ao de outras áreas, o que indica sinais de mudanças futuras no quadro de concentração industrial. Com base nos índices municipais, definiram-se 15 clusters com alto potencial de inovação, englobando 847 municípios, responsáveis por $60 \%$ do valor adicionado industrial do país.

PALAVRAS-CHAVE | Inovação; Indústria; Onet

Códigos-JEL | O30; L60; R12

* Faculdade de Economia, Administração e Contabilidade da Universidade de São Paulo (FEA - USP), São Paulo (SP), Brasil. E-mail: ednaldomorenogs@gmail.com.

** Faculdade de Economia, Administração e Contabilidade da Universidade de São Paulo (FEA - USP), São Paulo (SP), Brasil. E-mail: cazzoni@usp.br. 


\title{
The innovative potential of Brazilians regions in manufacturing
}

\begin{abstract}
This paper presents a new index to measure the innovative potential of the regions in manufacturing at the municipal level. The index jointly considers the technological level of the sectors, the occupations associated with $R \& D$ and the skills and other characteristics of workers. The index calculated for regions, states and municipalities for the period 2003-2012 shows that manufacturing in the South and Southeast regions still have the highest innovative potential. The evolution of the indices, however, shows that traditional areas grew less than other areas, indicating signs of future changes in the framework of industrial concentration. Based on the indexes for municipalities, we defined 15 clusters with high potential for innovation. These clusters encompass 847 municipalities, and account for $60 \%$ of the country's manufacturing value added.
\end{abstract}

KEYWORDS | Innovation; Manufacturing; Onet

JEL CODES | O30; L60; R12 


\section{Introdução}

Uma das várias observações empíricas das economias de aglomeração é a formação das concentrações industriais, principalmente em indústrias cuja inovação é tanto um importante insumo como um produto. Lemos et al. (2005) mostram que, no Brasil, as firmas mais inovadoras se aglomeram nos grandes centros urbanos, enquanto as mais tradicionais e conservadoras espalham-se pelas demais áreas.

A produtividade e o crescimento econômico estão cada vez menos baseados na abundância de recursos naturais e mais na capacidade de melhorar a qualidade do capital humano e dos fatores de produção e de criar novos conhecimentos e ideias, incorporando-os em equipamentos e pessoas (DAVID; FORAY, 2003). Cada vez mais o crescimento e o desempenho das economias nacionais e regionais parecem depender da geração, disseminação e aplicação de novos conhecimentos e inovações, particularmente envolvendo ciência e tecnologia (COOKE et al., 2007). Teorias recentes de crescimento econômico, como as de Lucas (1988) e Romer (1986, 1990), enfatizam o papel do capital humano na geração de novas ideias, inovações, tecnologias e transbordamentos locais, que geram ganhos de produtividade e sustentam o crescimento de longo prazo (FESER, 2003). Uma importante fonte de inovação está nas habilidades, educação e qualidade do mercado de trabalho local, que podem indicar o potencial inovativo das firmas aglomeradas. Analistas regionais estão redescobrindo a importância da força de trabalho em si, em vez da análise baseada nos setores e nas empresas locais, como um termômetro muito útil da força da economia local (MARKUSEN, 2002).

O objetivo do presente trabalho é avaliar a capacidade inovativa das regiōes brasileiras no setor industrial com um novo indicador, desenvolvido para suprir a falta de dados sobre a inovação propriamente dita. Para cada área, inclusive em nível municipal, gerou-se o Índice de Potencial Inovativo Regional (Ipir), com base nas habilidades dos trabalhadores que, em princípio, estão relacionadas com o processo inovativo e o transbordamento de conhecimento. Além dessas habilidades, utilizaram-se também informaçôes sobre o grau tecnológico de cada setor e a presença de ocupações intensivas em P\&D, já empregadas em outros trabalhos, gerando um indicador único de potencial inovativo. Assim, contribui-se para a literatura tanto por incorporar um aspecto inédito nos estudos sobre potencial inovativo regional no país - as habilidades dos trabalhadores - como por avançar no detalhamento geográfico, atingindo o nível municipal. 


\section{Revisão da literatura}

Firmas e trabalhadores são mais produtivos em grandes e densas áreas urbanas do que em outras localidades, além de as grandes cidades serem os locais onde a maioria das inovações substanciais ocorre. Uma parte significativa disso pode ser explicada pelas economias de aglomeração que, embora interessassem a todos os estudiosos do tema desde sempre, somente recentemente passaram a ser mais bem quantificadas (PUGA, 2010; BARUFI, 2015). Spillovers de conhecimento podem ocorrer por meio de relaçôes informais estabelecidas entre os agentes econômicos devido à proximidade geográfica (JAFFE et al., 1993), ou pela mobilidade de mão de obra entre firmas, principalmente de cientistas, engenheiros e outros trabalhadores, que podem possuir dotações de novos conhecimentos e que buscam por empresas que se interessem e valorizem adequadamente suas ideias (ANGEL, 1991; AUDRETSCH, 1998). Para Jacobs (1969), as vantagens da aglomeração estariam ligadas mais à diversificação de bens, serviços, tecnologias e conhecimentos próprios de um centro urbano, que fornecem terreno rico em criatividade e troca de informações e experiências entre diferentes setores. Vários estudos empíricos registram os chamados transbordamentos de conhecimento, como Anselin et al. (1997), Varga (1998), Döring e Schnellenbach (2004) e De Negri e Freitas (2004).

Porém, as firmas são distribuídas de forma desigual no espaço, dando origem a vários tipos de disparidades regionais nos fatores que afetam a capacidade de inovar. Universidades, centros de pesquisa, trabalhadores mais qualificados e atividades de inovação empresarial, como $\mathrm{P} \& \mathrm{D}$, patentes e inovaçôes de produto e processo, geralmente concentram-se em algumas regiōes específicas ou áreas (COOKE et al., 2007). Nos setores de alta tecnologia, vários estudos têm mostrado que as atividades de P\&D estão fortemente concentradas no espaço, muito mais do que o emprego ou a produção (COOKE, 2002; LAAFIA, 2002), o que leva, por sua vez, a disparidades de competência, produtividade, renda e oportunidade entre as localidades.

Dentre os fatores regionais, destaca-se neste artigo o mercado de trabalho, já que qualquer novo conhecimento inclui necessariamente a participação de pessoas. Quanto mais o mercado de trabalho for composto de trabalhadores com as habilidades que podem ser relevantes para inovar, maior é a capacidade de as firmas terem sucesso em suas buscas por novos produtos e processos. Soma-se a isso o já citado fato de que os trabalhadores exercem importante papel no transbordamento de conhecimento. Conforme Storper e Venables (2004), os contatos face-a-face entre os agentes, de maneira constante e estável, são um mecanismo importante 
para a transmissão de conhecimentos tácitos, principalmente se esses agentes tiverem as capacidades necessárias para absorver e utilizar tais conhecimentos. Isso foi confirmado no Brasil por Araújo e Garcia (2013), que documentaram a existência de amplas trocas de informações entre os trabalhadores das empresas de Tecnologia da Informação e Comunicação da região de Campinas.

Assim, analisando o mercado de trabalho de uma aglomeração, verificando o número de pesquisadores e de pessoas que trabalham diretamente com $\mathrm{P} \& \mathrm{D}$ e as habilidades importantes para o desenvolvimento de inovações dos trabalhadores em geral, pode-se ter uma noção do potencial de que inovações realmente se realizem. Araújo (2013) registra relação positiva e significante entre a atividade de P\&D da indústria nas microrregiões brasileiras (ocupações diretamente associadas a P\&D) e a inovação (patentes depositadas). Tal resultado é também visto nos trabalhos de Jaffe (1989) para os EUA, Moreno et al. (2005) para as regiōes europeias, Fritsch e Slavtchev (2007) para a Alemanha e Lemos et al. (2005), Gonçalves e Almeida (2009), Mascarini (2012) e Gonçalves e Farjado (2011) para o caso brasileiro.

A existência de poucos trabalhos no Brasil que utilizem diretamente gastos em $\mathrm{P} \& \mathrm{D}$ deve-se à falta dessas informaçôes, principalmente em recorte regional desagregado. A Pesquisa de Inovação - Pintec 2011, do IBGE, disponibiliza esses dados para as cinco regiōes brasileiras e apenas 14 estados, não captando devidamente a complexidade do processo (ROMEIRO et al., 2012). Mesmo com tais obstáculos, Mascarini (2012) conseguiu realizar um estudo quantitativo com esses dados, limitando-se às microrregiões do Estado de São Paulo. Montenegro et al. (2011) selecionaram, na Classificação Brasileira de Ocupações - CBO, físicos, químicos, engenheiros, analistas de sistemas e programadores como as ocupações mais relacionadas às atividades de $\mathrm{P} \& \mathrm{D}$ para estudarem a inovação nas microrregiōes paulistas, não encontrando relação significante entre a presença desses profissionais e a inovação nestas áreas. Ainda assim, os autores observaram que a qualificação dos trabalhadores é importante para o processo inovativo. Montenegro e Betarelli Jr. (2009), Mascarini (2012) e Araújo (2013), em que pese a mencionada limitação de dados, confirmaram a existência de clusters de alto desempenho inovativo concentrados no Estado de São Paulo. Araújo (2013) traz evidências da disparidade de inovação entre as Regiões Norte e Nordeste e as Regiōes Sul e Sudeste. Gonçalves e Farjado (2011), utilizando informações sobre depósitos de patentes, encontraram configurações regionais semelhantes para os clusters tecnológicos biofarmacêutico, desenvolvimento de novos materiais, bens mecânicos e de consumo e eletroeletrônicos. Albuquerque et al. (2002) revelaram que, no Brasil, as atividades tecnoló- 
gicas e científicas são mais concentradas do que as produtivas. Gonçalves (2007), trabalhando também com patentes, concluiu que o grau de industrialização, a escolaridade da população adulta, a presença de pesquisadores com doutorado, de trabalhadores em áreas de formação tecnológica e de diversidade industrial e tecnológica favorecem o processo de difusão dos transbordamentos de conhecimento nas microrregiões brasileiras. Todos esses trabalhos oferecem evidências de transbordamento de conhecimento e de que a inovação é mais presente em áreas mais industrializadas e demograficamente adensadas, apontando para economias de aglomeração marshallianas e jacobianas.

A limitação de informações é uma das inspirações para a busca da alternativa empírica apresentada neste trabalho. Enquanto alguns estudos limitam seu recorte regional ao nível estadual ou microrregional, outros enfrentam o problema de muitos locais do Brasil terem valores muito próximos de zero para suas medidas, o que dificulta a aplicação de modelos estatísticos. Em face dessa dificuldade, foi necessário aliar duas medidas indiretas de atividade de P\&D: a composição tecnológica setorial das empresas e o número de ocupações relacionadas a P\&D. Além disso, buscou-se evitar a utilização de um conjunto muito restrito de atividades, como apenas aquelas diretamente categorizadas como de P\&D, mas também nem tão abrangente que incluísse técnicos e profissionais que pouco contribuem para a inovação. Assim, buscou-se construir um índice que considere esses dois fatores e que dê importância à contribuição das ocupações no processo inovativo, sendo factível mesmo em nível municipal, dada a limitação de dados.

\section{Metodologia}

A quantificação do potencial inovativo das regiōes é uma tarefa complexa, como exemplifica o grande painel construído bienalmente pela OECD para os países (OCDE, 2015). Tendo em vista o objetivo de disponibilizar um indicador em nível geográfico desagregado, apresenta-se nesse trabalho um Índice de Potencial Inovativo Regional (Ipir) que combina três tipos de informação: a intensidade tecnológica do setor (IBGE, 2013), como em Mascarini (2012); a presença de ocupações mais relacionadas a P\&D, como em Montenegro et al. (2011); e um novo indicador, descrito a seguir. Oferecer informação desagregada geograficamente vem ao encontro da chamada "smart specialization", que se funda em políticas industriais bottom-up, ou "de baixo para cima", com foco em ativar ativos baseados em conhecimento (enabling knowledge-based assets) (OECD, 2013). Essa ativação, em nível regional, 
requer um mínimo de quantificação dos ativos disponíveis, no que o indicador aqui apresentado pode ter um papel relevante.

\subsection{Habilidades dos trabalhadores}

O Ipir procura avaliar a capacidade de inovar das aglomerações a partir das habilidades dos seus trabalhadores e no mix de ocupaçôes locais. O sentido de potencial utilizado aqui é que esse índice representa a capacidade da região de realizar uma inovação, principalmente com trabalhadores mais qualificados, em vez de utilizar dados que demonstram o número de inovaçóes já realizadas, como as patentes requeridas. Este trabalho baseia-se em Maciente (2013), que adaptou à realidade brasileira a base da Onet - Occupational Information Network, que associa a cada ocupação do mercado de trabalho americano um vasto conjunto de habilidades. ${ }^{1}$ As informações da Onet são divididas em seis principais domínios, sendo que neste trabalho utilizaram-se apenas variáveis dos seguintes domínios: características dos trabalhadores (habilidades, interesses e estilos de trabalho de cada ocupação); requisitos dos trabalhadores (perícias básicas e multifuncionais, conhecimento em geral e educação); e requisitos ocupacionais (atividades e o contexto organizacional do trabalho). As variáveis envolvendo habilidades, perícias, conhecimentos, interesses e estilos de trabalhos recebem duas classificações para cada ocupação: a primeira, numa escala de 1 (baixo) a 7 (alto), refere-se ao nível de profundidade que a ocupação requer; e a segunda, numa escala de 0 (irrelevante) a 5 (alto), corresponde à importância da variável em termos da centralidade e da frequência de uso nas atividades da ocupação (FESER, 2003). Maciente (2013) realizou o trabalho pioneiro de ligar as ocupações da Onet, baseadas na Standard Occupational Classification de 2010, com a CBO 2002, atribuindo às ocupações dessa última os valores das variáveis da Onet, fazendo adaptações e ajustes quando necessários.

Assim, foram atribuídas 263 variáveis da Onet para cada uma das 2.702 ocupações da CBO 2002, obtendo-se uma aproximação para o nível das habilidades das ocupações do mercado de trabalho brasileiro. Desse conjunto, selecionamos 61 variáveis associadas a potencial inovativo, que são as habilidades que podem ser diretamente utilizadas nas atividades inovativas. Além disso, como o objetivo do trabalho é avaliar a capacidade inovativa de uma região, e não de uma firma indi-

1 Para mais informaçōes, ver site oficial da Onet em <http://www.onetonline.org/>. 
vidualmente, foram também consideradas variáveis importantes para o processo de transbordamento de conhecimento que ocorre por meio dos trabalhadores de uma mesma localidade. Para tanto, foram selecionadas 26 variáveis associadas a spillovers de conhecimento, que refletem a possibilidade de transmitir e receber informações, conhecimentos e ideias das ocupações, impactando a capacidade inovativa das empresas vizinhas, por meio dos transbordamentos de conhecimento. ${ }^{2}$

Como as variáveis possuem alta correlação, aplicou-se o método da Análise de Componentes Principais (ACP) às 61 variáveis de potencial inovativo e às 26 de spillover de conhecimento (HAIR et al., 1998; MINGOTI, 2007). Constatou-se que $92 \%$ das correlaçôes entre pares das 61 variáveis de potencial inovativo e todas aquelas evolvendo as 26 variáveis de spillover de conhecimento são significativas a 1\%. Além disso, o teste de MSA, Kaiser's Measure of Sampling Adequacy, mostrou que apenas quatro das 87 variáveis ficaram abaixo de 0,8 , sendo que 76 situaram-se acima de 0,9. Os MSA totais dos dois grupos foram adequados e os testes de esfericidade de Bartlett foram significativos. ${ }^{3}$ Com isso, houve redução significativa do número de variáveis, sem perda de informaçôes contidas no grupo de variáveis originais.

Os resultados da ACP constam da Tabela $1 .{ }^{4}$ Levando em conta os resultados do teste da raiz latente, foram considerados os dez primeiros componentes de potencial inovativo, atingindo $81 \%$ da variância, e os quatro primeiros de spillover de conhecimento, compreendendo $85 \%$ da variância. Para facilitar a interpretação dos componentes, aplicou-se a rotação ortogonal Varimax a esses componentes, redistribuindo as cargas fatoriais sem alterar a variância total explicada por eles (HAIR et al., 1998). Observou-se, a partir dos valores e sinais das cargas fatoriais rotacionadas, que os componentes escolhidos possuem interpretação econômica clara. O primeiro e mais relevante componente de potencial inovativo possui cargas significativas em 20 das variáveis, explicando mais de $23 \%$ da variância, e pode ser identificado como representando a "capacidade de utilizar e gerar conhecimentos e de solucionar problemas". Todas as áreas do conhecimento incluídas nos componentes são importantes para gerar inovações, principalmente se associadas com as perícias e habilidades dos dois mais importantes componentes em questão de variância explicada. Quanto aos componentes de spillover de conhecimento, o primeiro

\footnotetext{
2 A lista completa das variáveis encontra-se no Apêndice.

3 Os resultados detalhados desses testes encontram-se no Apêndice.

4 Mais detalhes dos componentes extraídos da ACP estão no Apêndice.
} 
foi denominado "capacidade de expressão e compreensão", pois abrange um vasto número de habilidades e perícias de expressão, compreensão e comunicação, que estão intimamente ligadas. Os demais têm interpretação imediata.

TABELA 1

Componentes extraídos da Análise de Componentes Principais - ACP (1)

\begin{tabular}{lc}
\hline \multicolumn{1}{c}{ Componentes } & \% da Variância \\
\hline Potencial inovativo & \\
Capacidade de utilizar e gerar conhecimentos e de solucionar problemas & 23,6 \\
Capacidade de analisar e de processar dados, informaçóes e novos & 10,6 \\
conhecimentos & \\
Ciências sociais e capacidade de administrar e gerenciar & 8,0 \\
Ciências humanas e línguas & 7,7 \\
Ciências da saúde & 7,7 \\
Engenharia e design & 7,6 \\
Comunicação e pensamento criativo & 4,4 \\
Transporte, construção e segurança pública & 4,3 \\
Tecnologia da informação e comunicação (ICT) & 3,9 \\
Ciências naturais & 3,1 \\
Total & $\mathbf{8 0 , 9}$ \\
Spillover de conhecimento & \\
Capacidade de expressão e compreensão & 46,5 \\
Capacidade de treinar, ensinar e instruir & 13,7 \\
Capacidade de socializar e cooperar & 12,5 \\
Capacidade de desenvolver e trabalhar em grupo e de interagir & 12,2 \\
Total & $\mathbf{8 4 , 9}$ \\
\hline
\end{tabular}

Fonte: Onet. Cálculos dos autores.

(1) Com rotação ortogonal (Varimax).

Em resumo, cada trabalhador, a partir da sua ocupação, apresenta 87 níveis de habilidades potencialmente ligadas à inovação. Esses níveis foram reduzidos a 14 pela ACP, sendo dez de potencial inovativo e quatro de spillover de conhecimento. Assim, cada trabalhador recebeu 14 notas, correspondentes aos pesos dos atributos da sua ocupação, em cada componente. As estatísticas descritivas dessas notas entre as ocupações encontram-se na Tabela 5 do Apêndice, revelando a grande disparidade existente. 


\subsection{Esforço inovativo e intensidade tecnológica dos setores}

A tarefa seguinte é integrar esse novo indicador a outras dimensões consideradas em estudos anteriores. ${ }^{5}$ Com base na relação "gastos em P\&D/receita líquida de vendas" observada na Pintec de 2000, o IBGE (2003) classificou os setores em quatro níveis de intensidade tecnológica: baixa (B), média baixa $(\mathrm{MB})$, média alta $(\mathrm{MA})$ e alta (A). ${ }^{6} \mathrm{~A}$ outra dimensão compreende o número de profissionais de alta qualificação e de pessoas ocupadas em atividades de $\mathrm{P} \& \mathrm{D}$, seguindo a classificação da $\mathrm{CBO}$ 2002, que define nove famílias, englobando 33 ocupações (BRASIL, 2010).7. Para fazer essa integração estimou-se o seguinte modelo de análise de variância (Anova): $I H a b_{m, s, a}=\beta_{0}+\beta_{1} A+\beta_{2} M A+\beta_{3} M B+\beta_{4} P \& D+\beta_{5}(A * P \& D)+\beta_{6}(M A * P \& D)+\beta_{7}(M B * P \& D)+u$

Onde: $A, M A$ e $M B$ são variáveis binárias da intensidade tecnológica dos setores, sendo a referência o setor $\mathrm{B} ; P \& D=1$ se a ocupação é associada diretamente a $\mathrm{P} \& \mathrm{D}$ ou zero, caso contrário; e $I H a b_{m, s, a}$ é o índice de habilidade, que é calculado pelo número de trabalhadores em cada ocupação multiplicado por sua respectiva nota em um dos componentes e dividido pelo número total de trabalhadores, gerando uma média para os trabalhadores do município em cada componente, sendo em seguida calculada a média dos 14 componentes. Os coeficientes $\beta_{1}, \beta_{2}, \beta_{3,} \beta_{4} \beta_{5} \beta_{6}$, e $\beta_{7}$ mostram o quanto as médias das outras categorias diferenciam-se do setor de baixa intensidade tecnológica e com ocupações não $\mathrm{P} \& \mathrm{D}{ }^{8}$

Os resultados para 2012, constantes da Tabela 7, do Apêndice, indicam que os coeficientes dos setores crescem com a intensidade tecnológica, mostrando que há requisitos crescentes de habilidades à medida que aumenta a intensidade tecnológica dos setores. Há também diferenças estatisticamente significantes entre as habilidades requeridas de trabalhadores diretamente envolvidos em atividades de P\&D, vis-à-vis aqueles não envolvidos nessas atividades.

Com os coeficientes desse modelo Anova, chegou-se aos pesos utilizados para incorporar simultaneamente as três dimensões no indicador, que constam da Tabe-

5 Jaffe (1989), Moreno et al. (2005), Fritsch; Slavtchev (2007), Montenegro et al. (2011), Araújo (2013), Lemos et al. (2005), Gonçalves; Almeida (2009) e Gonçalves; Farjado (2011).

6 A classificação foi convertida da CNAE 1.0 para a CNAE 2.0, para se adequar aos dados da Rais de 2012, conforme tabelas de conversão do IBGE e as similaridades tecnológicas.

7 A presença de ocupaçốes com atividades em P\&D é muito concentrada, sendo nula na maioria dos municípios. Isso não traz problemas ao índice, posto que, nesses casos, os trabalhadores apenas não receberão o peso adicional referente a esse tipo de atividade, mas a sua nota, correspondente às suas habilidades, serão consideradas normalmente. A concentração das atividades de P\&D fará apenas que as poucas localidades que têm a atividade recebam notas maiores, como o indicador pretende considerar.

8 Para mais detalhes dos modelos ANOVA, ver Kennedy (1998) e Gujarati (2006). 
la 2. Para facilitar a utilização, os pesos foram normalizados em relação ao maior efeito total (trabalhador envolvido em P\&D, no setor A). Atribuiu-se à categoria de referência (trabalhador não envolvido em $\mathrm{P} \& \mathrm{D}$, no setor $\mathrm{B}$ ) um peso de 0,02 , muito próximo de zero. Trabalhadores em ocupação diretamente associada a P\&D, atuando no setor A, têm $100 \%$ de suas habilidades incorporadas integralmente ao indicador (peso $=1$ ). Já trabalhadores que atuam no setor $\mathrm{B}$ e não diretamente em $\mathrm{P} \& \mathrm{D}$ têm apenas $2 \%$ de suas habilidades incorporadas. As outras categorias possuem pesos intermediários, como indica a Tabela 2. Como providência final, as distribuiçôes das 14 dimensões das 2.702 ocupações foram deslocadas para o primeiro quadrante, para que todas as notas tenham valor positivo, ${ }^{9}$, a menor sendo igual a um, alterando-se apenas as médias das notas, mas não os desvios-padrão.

TABELA 2

Pesos setoriais e de P\&D

\begin{tabular}{l|cc|c|c}
\hline \multirow{2}{*}{ Setores } & \multicolumn{2}{c|}{ Efeitos totais } & \multicolumn{2}{c}{ Efeitos normalizados - pesos } \\
\cline { 2 - 5 } & P\&D & Não P\&D & P\&D & Não P\&D \\
\hline Setor A & 2,38 & 0,44 & 1,00 & 0,18 \\
Setor MA & 2,28 & 0,18 & 0,96 & 0,08 \\
Setor MB & 2,24 & 0,08 & 0,94 & 0,03 \\
Setor B & 2,22 & - & 0,93 & 0,02 \\
\hline
\end{tabular}

Fonte: Rais 2012, Pintec 2000 e Onet. Cálculos dos autores.

\section{3. Índice de Potencial Inovativo Regional - Ipir}

Para se chegar ao indicador de um município específico em cada uma das 14 dimensões, foram somadas as notas correspondentes às habilidades de todos trabalhadores locais na indústria, ponderando pelos pesos correspondentes. Essa soma foi dividida pelo número total de trabalhadores do município, de modo que o indicador apresenta uma média da qualificação dos trabalhadores locais na dimensão. Como resultado, obtiveram-se 14 notas para cada município. O Ipir do município $i$ é a média aritmética simples desses 14 indicadores. $\mathrm{O}$ índice assume forma relativa, com valor mínimo de 0,13 e máximo de 12,08 entre os municípios. Aqueles com grande proporção de trabalhadores alocados em ocupaçóes que não requerem as habilidades associadas à inovação, que não são de setores de alta tecnologia e que não desempenham atividades típicas de P\&D, apresentam índices baixos; municípios com elevada proporção de trabalhadores em atividades ligadas a P\&D, em setores de alta tecnologia e em ocupa-

9 A ACP fornece resultados normalizados, o que implica em valores negativos e positivos para as notas. 
ções com habilidades associadas a inovação, registram valores altos. Os indicadores foram calculados para 2003 e 2012, para diferentes níveis geográficos.

Antes de mostrar os resultados na próxima seção, é importante destacar algumas limitações do Ipir. Ele foi calculado com dados da Relação Anual de Informações Sociais - Rais de 2003 e 2012, para permitir a comparação entre dos índices atuais com os do início da década. ${ }^{10}$. Porém, as variáveis da Onet foram retiradas da sua atualização de 2011. Assim, consideramos que as habilidades, perícias e conhecimentos das ocupações não se alteraram entre 2011 e 2012 e que eram as mesmas em 2003, o que pode não ocorrer, já que a tecnologia, as ocupações e o mercado de trabalho evoluem e mudam ao longo do tempo. Adicionalmente, os dados originais da ONET Onet são para as ocupações americanas, e podendo haver diferenças entre elas e as brasileiras, aspecto que Maciente (2013) procurou minimizar. Ainda assim, o autor alerta para as diferenças econômicas e educacionais entre os países, o que pode limitar a comparação entre os requisitos das ocupações americanas das similares no Brasil, particularmente as tecnologicamente intensivas, como aquelas em P\&D.

Esses dois aspectos podem ser relevantes no indicador que se busca desenvolver. Todavia, como o objetivo é comparar regiōes distintas quanto ao potencial inovativo, sua influência dependerá de haver viés espacial, tanto na classificação de atividades quanto na adaptação da Onet para a CBO. Se as habilidades americanas não são as mesmas brasileiras, isso somente será um problema sério no indicador se a composição de ocupações, em cada setor, for muito diferente entre regiões, e se sofrer alteração ao longo do tempo. Adicionalmente, como se acrescentará adiante, trabalhou-se com a desagregação setorial de cinco dígitos, o que torna a existência de heterogeneidade setorial/regional menos provável. Finalmente, como o trabalho de Maciente (2013) foi muito meticuloso, fazendo adaptações sempre que julgou necessário, as discrepâncias entre as ocupações americanas e brasileiras não devem ser muito pronunciadas. Por outro lado, não há como verificar se há algum viés espacial ou temporal nessas duas dimensões.

Por último, não foi possível acrescentar ao índice um peso para incorporar o fato de que as indústrias concentram em suas sedes as atividades de $\mathrm{P} \& \mathrm{D}$, para depois transferir a tecnologia para filiais em outras regiões. Como os dados obtidos na Rais não são identificados, apenas o número de trabalhadores em setores de alto nível tecnológico foi introduzido no índice. Aqui o viés seria claramente no sentido de superestimar o potencial inovativo das regiōes onde estão as unidades produtivas,

Somente a partir de 2003 os dados da Rais foram disponibilizados no padrão da CBO 2002. 
e de subestimá-lo nas regiōes das sedes - estas normalmente nas principais cidades. Em que pesem tais limitações, que afetam principalmente a evolução do Ipir, acredita-se que o ganho de informação relevante com o novo índice seja significativo.

\section{Resultados}

Os Ipir foram calculados a partir de dados municipais do número de empregos da Rais de 2003 e 2012, ao nível de cinco dígitos (ocupaçóes/sinônimos), separando por setor CNAE 2.0 no nível de cinco dígitos (classe) e para todos os municípios, estados e macrorregiôes. ${ }^{11}$.

\subsection{Resultados regionais e estaduais}

A Tabela 3 exibe os valores do Ipir de 2012 do país das macrorregiōes e dos estados, separando nas dimensões de potencial inovativo e spillover de conhecimento ${ }^{12}$. Como esperado, em 2012 as regiôes do Sul e Sudeste ficaram acima do nível nacional de Ipir, enquanto Norte, Nordeste e Centro-Oeste ficaram abaixo. A Zona Franca de Manaus torna o Ipir do AM o maior dentre os estados, muito acima do segundo lugar. Os estados do Sul e Sudeste aparecem nas primeiras posiçōes, com o RJ em segundo lugar, seguido de SP, RS, PA e SC, com seus polos industriais e de inovação mais desenvolvidos e não restritos às principais regiōes metropolitanas.

O Gráfico 1 mostra que o crescimento do Ipir ao longo do período foi bem desigual. Enquanto o índice nacional cresceu apenas 4,1\%, a Região Sul registrou aumento de $15,8 \%$, seguida pelo Nordeste $(9,4 \%)$ e Centro-Oeste (9,3\%). Isto é, além de suas produções industriais terem crescido mais do que no Sudeste entre 2003 e 2012, essas regiōes obtiveram elevação maior no grau inovativo, indicando que o lento processo de desconcentração industrial inter-regional não ocorreu apenas em setores de menor tecnologia e indústrias potencialmente menos inovativas. Porém, o processo de aperfeiçoamento tecnológico do parque industrial do Nordeste e Centro-Oeste é lento, pois em 2012 ainda ficaram, respectivamente, na penúltima e na última posição do Ipir. Embora perdendo vantagem, o Sudeste ainda permanece como o principal parque industrial do país, do ponto de vista do potencial inovativo.

11 A análise poderia também ter sido feita por micro ou meso rregiōes, assim como para as regiōes do estudo Regic, do IBGE (IBGE, 2008), ou para os arranjos populacionais, do mesmo Instituto (IBGE, 2015). Considerando que adiante se constituirão clusters de municípios por potencial aglomerativo, decidiu-se apresentar os resultados nesses três níveis geográficos.

12 A tabela com o Ipir de 2003 encontra-se no Apêndice. 
TABELA 3

Índice de Potencial Inovativo Regional - Ipir

Brasil - 2012

\begin{tabular}{|c|c|c|c|c|c|c|}
\hline \multirow[b]{2}{*}{ Regióes } & \multicolumn{2}{|r|}{ Ipir } & \multicolumn{2}{|c|}{ Potencial inovativo } & \multicolumn{2}{|c|}{$\begin{array}{c}\text { Spillover de } \\
\text { conhecimento }\end{array}$} \\
\hline & Valor & $\begin{array}{c}\text { Taxa de } \\
\text { crescimento } \\
2003-12(\%)\end{array}$ & Valor & $\begin{array}{c}\text { Taxa de } \\
\text { crescimento } \\
2003-12(\%)\end{array}$ & Valor & $\begin{array}{c}\text { Taxa de } \\
\text { crescimento } \\
2003-12(\%)\end{array}$ \\
\hline Brasil & 0,455 & 4,10 & 0,461 & 4,05 & 0,438 & 4,24 \\
\hline Sudeste & 0,520 & 2,47 & 0,527 & 2,45 & 0,503 & 2,52 \\
\hline Sul & 0,459 & 15,83 & 0,467 & 15,54 & 0,440 & 16,59 \\
\hline Norte & 0,448 & $-4,74$ & 0,453 & $-4,55$ & 0,436 & $-5,23$ \\
\hline Nordeste & 0,308 & 9,39 & 0,313 & 9,35 & 0,295 & 9,48 \\
\hline Centro-Oeste & 0,282 & 9,35 & 0,287 & 9,67 & 0,270 & 8,52 \\
\hline $\mathrm{AM}$ & 0,810 & $-6,75$ & 0,816 & $-6,74$ & 0,796 & $-6,78$ \\
\hline RJ & 0,599 & 20,32 & 0,605 & 20,37 & 0,582 & 20,17 \\
\hline SP & 0,562 & 1,42 & 0,569 & 1,35 & 0,544 & 1,59 \\
\hline RS & 0,495 & 14,54 & 0,503 & 14,18 & 0,473 & 15,49 \\
\hline PA & 0,443 & 17,18 & 0,450 & 17,53 & 0,427 & 16,27 \\
\hline SC & 0,435 & 19,50 & 0,442 & 19,13 & 0,418 & 20,46 \\
\hline DF & 0,415 & 34,30 & 0,418 & 34,80 & 0,406 & 33,03 \\
\hline MG & 0,398 & 4,20 & 0,404 & 4,28 & 0,382 & 3,99 \\
\hline BA & 0,367 & $-6,03$ & 0,373 & $-5,86$ & 0,354 & $-6,47$ \\
\hline ES & 0,347 & 11,34 & 0,353 & 11,16 & 0,332 & 11,82 \\
\hline $\mathrm{AP}$ & 0,342 & $-2,16$ & 0,346 & $-2,48$ & 0,333 & $-1,33$ \\
\hline PE & 0,342 & 19,59 & 0,347 & 19,63 & 0,329 & 19,50 \\
\hline MA & 0,331 & 11,74 & 0,337 & 11,98 & 0,318 & 11,10 \\
\hline GO & 0,304 & 5,90 & 0,309 & 6,16 & 0,291 & 5,20 \\
\hline CE & 0,293 & 14,65 & 0,298 & 14,14 & 0,280 & 16,04 \\
\hline SE & 0,282 & $-0,88$ & 0,288 & $-0,25$ & 0,268 & $-2,52$ \\
\hline $\mathrm{RR}$ & 0,279 & 34,43 & 0,283 & 34,68 & 0,271 & 33,78 \\
\hline PI & 0,277 & $-2,48$ & 0,281 & $-2,48$ & 0,266 & $-2,50$ \\
\hline TO & 0,273 & 14,92 & 0,279 & 15,50 & 0,260 & 13,39 \\
\hline PR & 0,268 & 16,08 & 0,272 & 16,00 & 0,256 & 16,27 \\
\hline MS & 0,262 & 17,63 & 0,267 & 17,96 & 0,248 & 16,77 \\
\hline $\mathrm{RO}$ & 0,254 & 19,29 & 0,258 & 19,62 & 0,243 & 18,43 \\
\hline $\mathrm{RN}$ & 0,252 & $-1,37$ & 0,256 & $-1,22$ & 0,241 & $-1,75$ \\
\hline $\mathrm{PB}$ & 0,238 & $-2,17$ & 0,242 & $-2,11$ & 0,227 & $-2,35$ \\
\hline MT & 0,237 & 10,75 & 0,241 & 11,00 & 0,226 & 10,07 \\
\hline $\mathrm{AC}$ & 0,236 & 8,01 & 0,239 & 8,50 & 0,227 & 6,74 \\
\hline $\mathrm{AL}$ & 0,200 & 12,08 & 0,205 & 12,02 & 0,188 & 12,24 \\
\hline
\end{tabular}

Fonte: Rais 2012, Pintec 2000 e Onet. Cálculos dos autores. 


\section{GRÁFICO 1}

Índice de Potencial Inovativo Regional - Ipir e taxas de crescimento

Unidades da Federação - 2003-2012

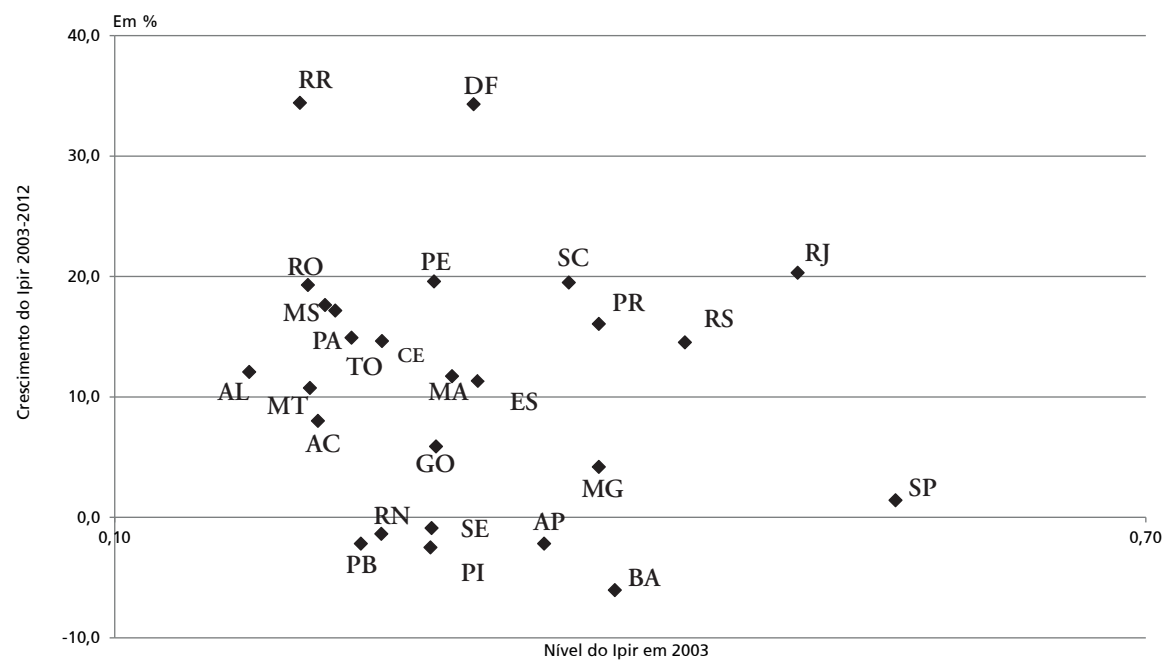

Fonte: Rais 2003 e 2012, Pintec 2000 e Onet. Cálculos dos autores.

\subsection{Resultados municipais}

O Mapa 1 mostra os resultados municipais, em oito faixas de valores do Ipir. Pelos argumentos teóricos apresentados anteriormente, com respeito ao papel das economias de aglomeração e de transbordamento de conhecimento, foram considerados apenas municípios com mais de 30 empregos industriais e que respondiam por pelo menos $0,02 \%$ do valor adicionado industrial nacional, o que excluiu 20\% dos 5.564 municípios da amostra. Observa-se uma concentração de índices altos no Sudeste e no Sul, como esperado, mas há casos desse tipo também em alguns municípios fora dessa área industrial tradicional, especializados em atividades associadas a recursos naturais, como a agroindústria e o processamento de minérios.

\subsection{Clusters de inovação}

Buscou-se também identificar aglomerações de municípios com alto potencial de inovação, tendo em vista os argumentos apresentados na revisão teórica a respeito da importância da proximidade e da aglomeração para o processo inovativo. Aplicou-se a análise exploratória de dados espaciais (Aede), calculando-se o indicador I de 
Moran para o Ipir dos municípios, ${ }^{13}$, cujos resultados revelaram indícios de forte padrão de clusterização do potencial inovativo. ${ }^{14}$ Basicamente, um cluster é formado por municípios com alto potencial inovativo, cercados de municípios contíguos com igual condição. Municípios com alto potencial, porém cercados de outros com baixo potencial (como Manaus), não chegam a formar um cluster. O Mapa 1 exibe, além dos municípios destacados na subseção anterior, os clusters de inovação encontrados em 2012, seguindo os padrôes da literatura de clusters industriais, ou seja, considerando o nível de significância de $10 \%$ e uma matriz de vizinhança do tipo Rainha ${ }^{15}$ (LEMOS et al., 2005; GONÇALVES; ALMEIDA, 2009). Além disso, o cluster deve ter uma média do Ipir dos municípios que o compóem de no mínimo 0,35. Vale salientar que o corte de 0,35 na média dos índices municipais dos clusters é um valor alto, quando comparado à média de todos os municípios brasileiros $(0,25)$.

Foram identificados 15 clusters de inovação, expostos na Tabela 4 e no Mapa 1, englobando 847 municípios, responsáveis por quase $60 \%$ do valor adicionado industrial do país. Desses, 93\% são das Regiōes Sul e Sudeste, representando 92\% do valor adicionado industrial do conjunto dos municípios pertencentes a clusters de inovação e 55\% do valor adicionado industrial do país. No Nordeste há dois clusters, em torno de Recife e Salvador, sendo que este último ficou com a quarta maior média no índice, pouco abaixo do cluster do Rio de Janeiro. No Sudeste, o cluster do RJ obteve a maior média, seguido por Belo Horizonte, São Paulo, Ribeirão Preto, Marília e Vitória, novamente evidenciando o desenvolvimento industrial dessa parte do país. Já no Sul, destacam-se Porto Alegre, Curitiba-Joinville e Caxias do Sul.

Utilizando essa abordagem setorial, Lemos et al. (2005) chegam a resultados para o ano de 2000 parecidos com os obtidos aqui, considerando-se a evolução das aglomeraçóes industriais nos 12 anos de diferença entre os dados dos dois trabalhos. Eles identificaram a aglomeração de Volta Redonda como a mais inovativa em 2000, seguida pela de São Paulo. No presente trabalho, essa aglomeração pertence

13 I de Moran é uma medida de autocorrelação espacial global dos dados, muito utilizada para averiguar se há efeitos de transbordamentos entre vizinhos e qual é a direção da autocorrelação: se positiva ou negativa, ou seja, se vizinhos costumam apresentar desvios similares em relação à média. Um I de Moran positivo indica a existência de clusters nos dados. Foi empregado nível de significância de 10\%, típico de trabalhos nesta área (ANSELIN, 1997). Em Góis-Sobrinho (2014), em que se baseia este artigo, foram utilizados outros níveis de significância, com pouca alteração nos resultados.

14 Gonçalves (2007) também utiliza essa metodologia em sua análise do padrão espacial da atividade inovadora brasileira.

15 Outras matrizes de vizinhança foram utilizadas, sem mudanças importantes nos resultados. Para mais detalhes técnicos, ver Góis-Sobrinho (2014). 
ao cluster do Rio de Janeiro, que possui o maior potencial inovativo, com São Paulo perdendo espaço e ficando em quarto lugar, logo abaixo de Belo Horizonte. A maior diferença está no cluster de Salvador, que, no trabalho de Lemos et al. (2005), ficou entre os menos inovativos, enquanto aqui está em segundo lugar. Isso pode ser mais uma evidência do aperfeiçoamento tecnológico do parque industrial do Nordeste na década passada.

\section{MAPA 1}

Índice de Potencial Inovativo Regional - Ipir municipal e clusters de inovação 2012

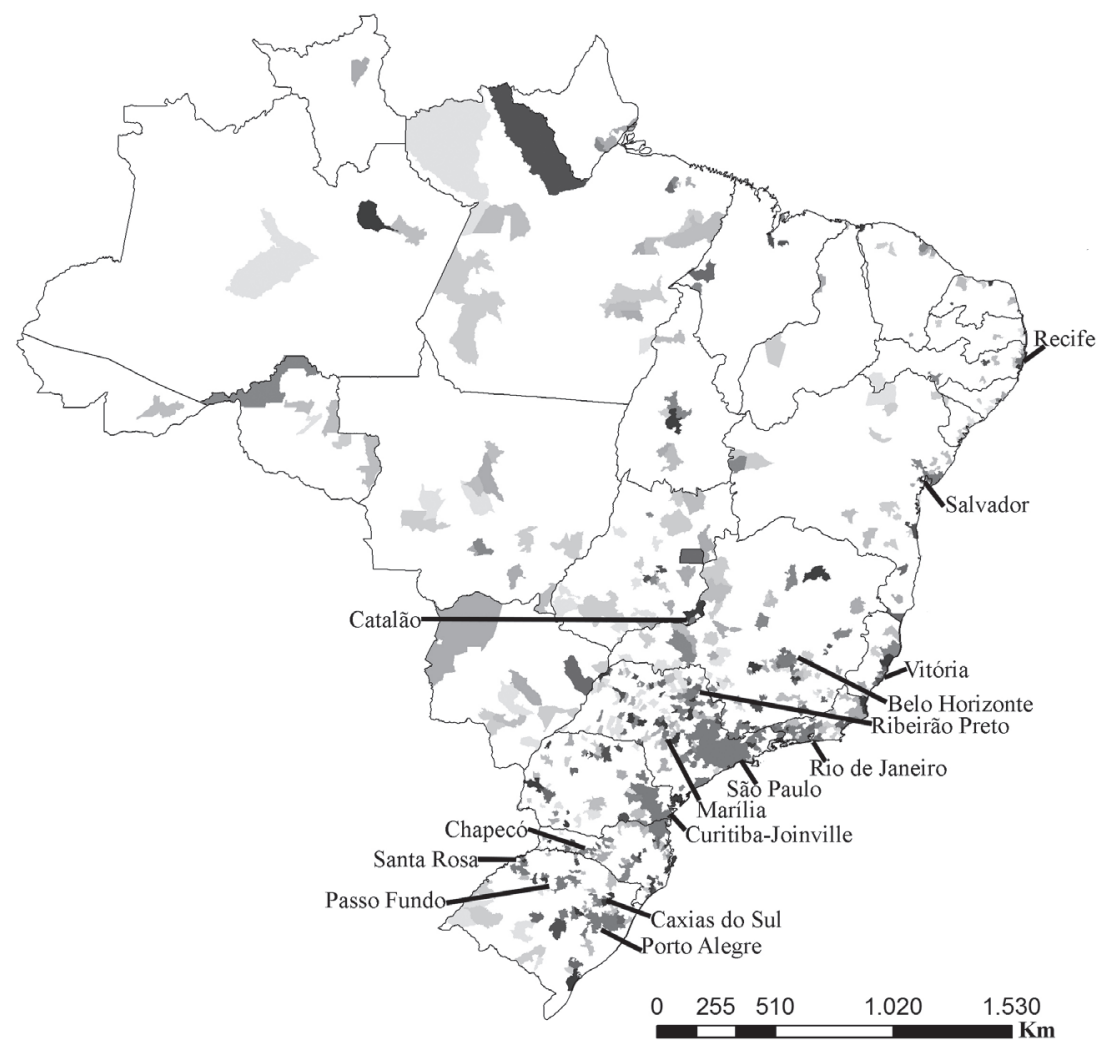

Legenda

Índice de Potencial Inovativo de 2012

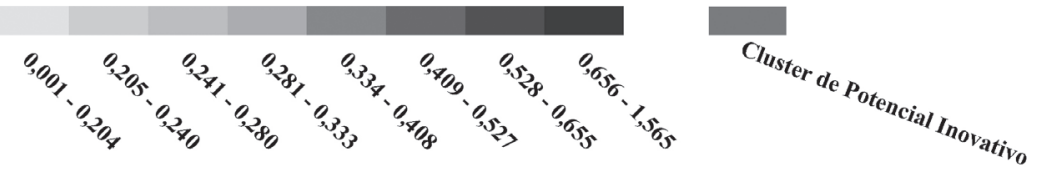

Fonte: Rais 2012, Pintec 2000 e Onet. Cálculos dos autores. 
O Gráfico 2 dispõe os níveis do Ipir em 2003 e o crescimento no período 2003-2012. Verifica-se que o cluster de inovação de São Paulo perdeu força e diminuiu significativamente sua extensão no período 2003-2012, contra aumentos em Curitiba-Joinville, na Região Sul. No entanto, dado o alto Ipir do Sudeste em 2012, esses resultados podem apenas refletir um deslocamento do dinamismo desses clusters para outras localidades, como é apontado na literatura (DOMINGUES; RUIZ, 2008; CRUZ; SANTOS, 2009; CAMPOLINA et al., 2012). Todavia, uma regressão simples associando o crescimento e o nível inicial do Ipir nos clusters revelou não haver relação estatisticamente significante entre as variáveis. Assim, não se pode afirmar que exista qualquer regularidade estatisticamente defensável entre níveis iniciais e crescimento do potencial inovativo.

\section{TABELA 4}

Clusters de inovação

Brasil - 2012

\begin{tabular}{|c|c|c|c|c|c|c|c|}
\hline Regióes & UF & $\begin{array}{c}\text { Número } \\
\text { de } \\
\text { municípios }\end{array}$ & $\begin{array}{c}\text { Média } \\
\text { do Ipir } \\
\text { municipal }\end{array}$ & $\begin{array}{l}\text { Média do } \\
\text { potencial } \\
\text { inovativo }\end{array}$ & $\begin{array}{c}\text { Média do } \\
\text { spillover de } \\
\text { conhecimento }\end{array}$ & $\begin{array}{c}\text { Era } \\
\text { cluster de } \\
\text { inovaçáo } \\
\text { em 2003? }\end{array}$ & $\begin{array}{c}\text { Participação } \\
\text { no VAB } \\
\text { industrial } \\
\text { nacional de } \\
2010(\%)\end{array}$ \\
\hline Nordeste & & 52 & 0,450 & 0,455 & 0,438 & & 4,42 \\
\hline Salvador & $\mathrm{BA}$ & 30 & 0,433 & 0,438 & 0,420 & Sim & 2,95 \\
\hline Recife & PE & 22 & 0,379 & 0,383 & 0,368 & Sim & 1,47 \\
\hline Centro-Oeste & & 7 & 0,364 & 0,369 & 0,350 & & 0,20 \\
\hline Catalão & $\mathrm{GO}$ & 7 & 0,364 & 0,369 & 0,350 & Sim & 0,20 \\
\hline Sudeste & & 472 & 0,394 & 0,400 & 0,377 & & 43,31 \\
\hline Rio de Janeiro & RJ & 51 & 0,434 & 0,441 & 0,419 & Sim & 6,05 \\
\hline Belo Horizonte & MG & 38 & 0,425 & 0,431 & 0,409 & Sim & 4,24 \\
\hline São Paulo & SP & 283 & 0,424 & 0,431 & 0,407 & Sim & 28,62 \\
\hline Ribeirão Preto & SP & 60 & 0,371 & 0,378 & 0,351 & Sim & 2,02 \\
\hline Marília & SP & 18 & 0,356 & 0,362 & 0,34 & Sim & 0,20 \\
\hline Vitória & ES & 22 & 0,354 & 0,36 & 0,338 & Sim & 2,18 \\
\hline Sul & & 316 & 0,380 & 0,387 & 0,361 & & 11,90 \\
\hline Porto Alegre & RS & 80 & 0,408 & 0,416 & 0,387 & Sim & 3,92 \\
\hline Passo Fundo & RS & 43 & 0,398 & 0,406 & 0,379 & Sim & 0,34 \\
\hline Santa Rosa & RS & 35 & 0,395 & 0,403 & 0,376 & Sim & 0,20 \\
\hline Curitiba-Joinville & $\mathrm{PR} / \mathrm{SC}$ & 91 & 0,390 & 0,397 & 0,373 & Sim & 5,67 \\
\hline Caxias do Sul & RS & 31 & 0,362 & 0,37 & 0,343 & Sim & 1,15 \\
\hline Chapecó & SC & 36 & 0,354 & 0,361 & 0,338 & Sim & 0,62 \\
\hline Média/Total & & 847 & 0,402 & 0,408 & 0,386 & & 59,83 \\
\hline
\end{tabular}

Fonte: Rais 2012, Pintec 2000 e Onet. Cálculos dos autores. 
GRÁFICO 2

Níveis e crescimento do Ipir nos clusters de inovação

2003-2012

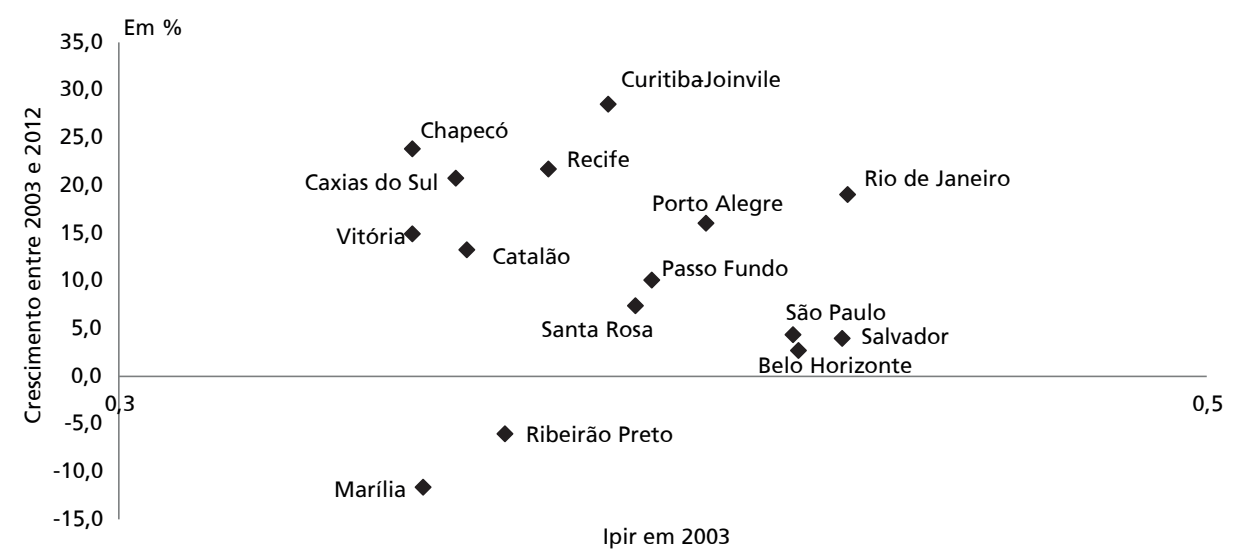

Fonte: Rais 2003 e 2012, Pintec 2000 e Onet Cálculos dos autores.

\section{Considerações finais}

Este trabalho oferece uma nova medida da capacidade de inovação das regiōes brasileiras, procurando sobrepujar a falta de informações específicas em nível geográfico desagregado. Essa medida leva em conta três dimensões: as habilidades dos trabalhadores correspondentes a cada ocupação; a intensidade tecnológica do setor em que a ocupação ocorre; e a associação da atividade desenvolvida com P\&D. As duas últimas dimensões já foram consideradas em estudos anteriores, mas a primeira é inédita na literatura brasileira. Para a identificação de indicadores da primeira dimensão, foi utilizada a adaptação para o Brasil do estudo americano que associa habilidades a ocupações naquela realidade, feita em Maciente (2013). Cada trabalhador na indústria, a partir de sua ocupação, apresenta 87 níveis de habilidades ligadas à inovação, que foram reduzidos a 14 a partir da aplicação da análise de componentes principais. Foram assim gerados, para cada trabalhador, 14 valores, que indicam sua capacidade potencial para contribuir com a inovação.

O Ipir atinge valores baixos para regióes com grande proporção de trabalhadores alocados em ocupações que não requerem as habilidades associadas à inovação, que não são de setores de alta tecnologia e que não desempenham atividades típicas de P\&D; já regiôes com elevada proporção de trabalhadores em atividades com essas três dimensões apresentam valores altos para o índice. Construíram-se Índices de Potencial Inovativo Regional para macrorregiōes, estados, e municípios. Descer a 
esses níveis de desagregação geográfica não é possível a partir dos dados da Pintec, que oferece apenas informações em âmbito estadual. Foram calculados índices para 2003 e 2012, possibilitando obter-se uma ideia da evolução do potencial inovativo das regiōes brasileiras no período.

Foram identificados 15 clusters de inovação, envolvendo 847 municípios, que representavam quase $60 \%$ do valor adicionado bruto da indústria no país em 2012. A análise da variação do potencial inovativo ao longo do período 20032012 permite destacar baixo crescimento nos clusters do Sudeste, com exceção do Rio de Janeiro, e alto crescimento dos clusters do Sul. No Nordeste, sobressaem o importante crescimento do cluster de Recife e modesto no caso do cluster de Salvador. A associação entre níveis iniciais de potencial inovativo e seu crescimento ao longo do período não mostrou relação estatisticamente significante, apontando para a manutenção do status quo da dispersão espacial do potencial inovativo, em termos gerais.

\section{Referências bibliográficas}

AlBUQUERQUE, E. M.; SIMÕES, R.; BAESSA, A.; CAMPOLINA, B.; SILVA, L. A distribuição espacial da produção científica e tecnológica brasileira: uma descrição de estatísticas de produção local de patentes e artigos científicos. Revista Brasileira de Inovação, v. 1, n. 2, p. 225-251, 2002.

ANGEL, D. P. High technology agglomeration and the labour market: the case of Silicon Valley. Environment and Planning A, v. 23, p. 1501-1516, 1991.

ANSELIN, L. Local indicator of spatial association - LISA. Geographical Analysis, v. 27, n. 3, p. 93-115, 1995.

ANSELIN, L.; VARGA, A.; ACS, Z. Local geographic spillovers between university research and high technology innovations. Journal of Urban Economics, v. 24, p. 422-448, 1997.

ARAújO, V. de C. Dimensão local da inovação no Brasil: determinantes e efeitos de proximidade. Tese (Doutorado) - Escola Politécnica, Universidade de São Paulo - USP, São Paulo, 2013.

ARAÚJO, V. de C.; GARCIA, R. Transbordamentos locais de conhecimento por meio de contatos informais: uma análise a partir do sistema local de indústrias TIC de Campinas. Revista Brasileira de Inovação, v. 12, n. 1, p.105-132, 2013.

AUDRETSCH, D. B. Agglomeration and the location of innovative activity. Oxford Review of Economic Policy, v. 14, n. 2, p. 18-29, 1998. 
BARUFI, A. M. B. Agglomeration economies and labour markets in Brazil. Tese (Doutorado) Faculdade de Economia e Administração, Universidade de São Paulo - USP, São Paulo, 2015. BRASIL. Ministério do Trabalho e Emprego - MTE. Livro 1 - Classificação Brasileira de Ocupaçôes. 3. ed. Brasília: MTE, SPPE, 2010.

CAMPOLINA, B.; PAIXÃO, A. N. da; REZENDE, A. C. de. Clusterização e localização da indústria de transformação no Brasil entre 1994 e 2009. Revista Econômica do Nordeste, Fortaleza, v. 43, n. 4, p. 27-49, 2012.

COOKE, P. Knowledge economies. London: Routledge, 2002.

COOKE, P.; DE LAURENTIS, C.; TODTLING, F.; TRIPPL, M. Regional Knowledge economies: markets, clusters and innovation. Massachusetts: Edward Elgar Publishing Inc., 2007.

CRUZ, B. de D.; SANTOS, Y. R. S. dos. Dinâmica do emprego industrial no Brasil entre 1990 e 2007: uma visão regional da desindustrialização. Boletim Regional, Urbano e Ambiental, , v. 2, 2009.

DAVID, P.; FORAY, D. Economic fundamentals of the knowledge society. Policy Futures in Education, v. 1, p. 20-49, 2003.

DE NEGRI, J. A.; FREITAS, F. Inovação tecnológica, eficiência de escala e exportaçôes brasileiras. Brasília: Ipea, 2004 (Texto para discussão n. 1044).

DOMINGUES, E. P.; RUIZ, R. M. Aglomerações econômicas no Sul-Sudeste e no Nordeste brasileiro: estruturas, escalas e diferenciais. Estudos Econômicos, São Paulo, v. 38, n. 4, p. 701-746, 2008.

DÖRING, T.; SCHNELLENBACH, J. What do we know about geographical knowledge spillovers and regional growth? A survey of the literature. Deutsche Bank Research. 2004.

FESER, E. J. What regions do rather than make: a proposed set of knowledge-based occupation clusters. Urban Studies, v. 40, n. 10, p. 1937-1958, 2003.

FRITSCH, M.; SLAVTCHEV, V. Universities and innovation in space. Industrial Innovation, v. 14, p. 201-218, 2007.

GÓIS-SOBRINHO, E. M. A localização e o grau inovativo das aglomerações industriais relevantes do Brasil. Dissertação (Mestrado) - Instituto de Pesquisas Econômicas - IPE, Universidade de São Paulo - USP, São Paulo, 2014.

GONÇALVES, E. O padrão espacial da atividade inovadora brasileira: uma análise exploratória. Estudos Econômicos, São Paulo, v. 37, n. 2, p. 405-433, 2007.

GONÇALVES, E.; ALMEIDA, E. S. Innovation and spatial knowledge spillovers: evidence from Brazilian patent data. Regional Studies, v. 43, p. 513-528, 2009. 
GONÇALVES, E.; FAJARDO, B. A. G. A influência da proximidade tecnológica e geográfica sobre a inovação regional no Brasil. Revista Econômica Contemporânea, v. 15, n. 1, p. 112-142, 2011.

GUJARATI, D. N. Econometria básica. 4. ed. Rio de Janeiro: Elsevier, 2006.

HAIR, J. F. JR.; ANDERSON, R. E.; TATHAM, R. L.; BLACK, W. C. Multivariate data analysis. 5. ed. USA: Prentice Hall, 1998.

IBGE - Instituto Brasileiro de Geografia e Estatística. Pesquisa Industrial, v. 22, n. 1, p. 4-9, 2003.

Regiôes de influência das cidades - 2007. Rio de Janeiro, 2008. Disponível em: <http://www.ibge.gov.br/home/geociencias/geografia/regic.shtm>.

Pesquisa de Inovação 2011. Rio de Janeiro, 2013. Disponível em: <http:// biblioteca.ibge.gov.br/visualizacao/livros/liv81830.pdf>.

- Arranjos populacionais e concentraçôes urbanas no Brasil. Rio de Janeiro, 2015.

Disponível em: <www.ibge.gov.br/apps/arranjos_populacionais/2015>.

JACOBS, J. The economy of cities. New York: Vintage, 1969.

JAFFE, A. B. Real effects of academic research. American Economic Review, v. 79, n. 5, p. 957-970, 1989.

JAFFE, A. B.; TRAJTENBERG, M.; HENDERSON, R. Geographic localization of knowledge spillovers as evidenced by patent citations. Quarterly Journal of Economics, v. 108, n. 3, p. 577-598, 1993.

KENNEDY, P. A guide to econometrics. 4. ed. Cambridge: MIT Press, 1998.

LAAFIA, I. National and regional employment in high tech and knowledge intensive sector in the EU, 1995-2000. Statistics in Focus, Science and Technology, Eurostat, 2002.

LEMOS, M. B.; MORO, S.; DOMINGUES, E. P.; RUIZ, R. M. A organização territorial da indústria no Brasil. In: DE NEGRI, J. A.; SALERMO, M. (Org.). Inovação, padrões tecnológicos e desempenho das firmas industriais brasileiras. Brasília: Ipea, 2005. p. 325-363.

LUCAS JR., R. E. On the mechanics of economic development. Journal of Monetary Economics, v. 22, p. 03-42, 1988.

MACIENTE, A. N. The determinants of agglomeration in Brazil: input-output, labor and knowledge externalities. Tese (Doutorado) - University of Illinois at Urbana-Champaign, Illinois, 2013. 
MARKUSEN, A. Targeting occupations rather than industries in regional and community economic development. Minneapolis: Humphrey Institute of Public Affairs, 2002. Unpublished manuscript. Disponível em: <http://citeseerx.ist.psu.edu/viewdoc/download?doi=10.1.1.19 4.6382\&rep=rep1\&type $=$ pdf $>$.

MASCARINI, S. M. S. Fatores territoriais da inovação: uma análise empírica das relaçóes entre os insumos inovativo e os resultados da inovação aplicada às microrregiōes paulistas. Dissertação (Mestrado) - Universidade Estadual de Campinas - Unicamp, Campinas, 2012. MINGOTI, S. A. Análise de dados através de métodos de estatística multivariada: uma abordagem aplicada. Belo Horizonte Universidade Federal de Minas Gerais - UFMG, 2007 (Texto técnico).

MONTENEGRO, R. L.; GONÇALVES, E.; ALMEIDA. E. S. Dinâmica espacial e temporal da inovação no estado de SP: uma análise das externalidades de diversificação e especialização. Estudos Econômicos, v. 41, n. 4, p. 743-776, 2011.

MONTENEGRO, R. L. G.; BETARELli JR., A. A. Análise e investigação dos fatores determinantes da inovação nos municípios de SP. Revista da Associação Brasileira de Estudos Regionais e Urbanos, v. 2, n. 2, 2011.

MORENO, R.; PACI, R.; USAI, S. Spatial spillovers and innovation activity in European regions. Environment and Planning A, v. 37, p. 1793-1812, 2005.

OECD - Organisation for Economic Co-operation and Development. Innovation-driven growth in regions: the role of smart specialization. 2013. Disponível em: <http://www.oecd. org/innovation/inno/smart-specialisation.pdfs.

OECD science, technology and industry scoreboard 2015: innovation for growth and society. Paris: OEDC Publishing, 2015. Disponível em: <http://dx.doi.org/10.1787/ sti_scoreboard-2015-en>.

PUGA, D. The magnitude and causes of agglomeration economies. Journal of Regional Science, v. 50, n. 1, p. 203-219, 2010.

ROMEIRO, M. do C.; PREARO, L. C.; SIlveirA, M. A. P. da; NETO, J. de P. R. Pesquisa sobre Inovação Tecnológica: o possível viés da informação em levantamentos. Revista Brasileira de Inovação, v. 13, n. 1, p. 133-162, 2014.

ROMER, P. M. Increasing returns and long-run growth. Journal of Political Economy, v. 94, n. 5, p. 1002-1037, 1986. 
71-100, 1990.

. Endogenous technological change. Journal of Political Economy, v. 98, n. 5, p.

STORPER, M.; VENABLES, A. J. Buzz: face-to-face contact and the urban economy. Journal of Economic Geography, v. 4, p. 351-370, 2004.

VARGA, A. Local academic knowledge spillovers and the concentration of economic activity. Morgantown: Regional Research Institute, West Virginia University, 1998 (Research paper, n. 9803). 


\section{Apêndice}

TABELA 1

Habilidades dos trabalhadores relacionadas à inovação e aos testes estatísticos para aplicação da ACP

\begin{tabular}{|c|c|c|c|}
\hline Variáveis de potencial inovativo & MSA & Língua inglesa & 0,9604 \\
\hline Fluência de ideias & 0,9576 & Língua estrangeira & 0,908 \\
\hline Originalidade & 0,9549 & Artes & 0,7921 \\
\hline Sensibilidade a problemas & 0,9718 & História e arqueologia & 0,8583 \\
\hline Flexibilidade para agrupar & 0,9775 & Filosofia e teologia & 0,9557 \\
\hline Rapidez de conclusão & 0,9542 & Defesa e segurança pública & 0,8283 \\
\hline Flexibilidade para concluir & 0,943 & Lei e governo & 0,9429 \\
\hline Investigativo & 0,9677 & Telecomunicações & 0,8719 \\
\hline Condiçôes de trabalho & 0,9716 & Comunicações e mídia & 0,8497 \\
\hline Reconhecimento & 0,9609 & Obter informaçōes & 0,9791 \\
\hline Criatividade & 0,9783 & Identificar objetos, açôes e eventos & 0,9681 \\
\hline Adaptável/flexível & 0,9626 & Processar informações & 0,9585 \\
\hline Atenção aos detalhes & 0,9387 & Analisar dados ou informaçóes & 0,962 \\
\hline Inovativo & 0,949 & Pensar criativamente & 0,9545 \\
\hline Pensamento analítico & 0,9729 & $\begin{array}{l}\text { Atualizar e utilizar conhecimentos } \\
\text { relevantes }\end{array}$ & 0,9709 \\
\hline Habilidade matemática & 0,9408 & Documentar/gravar informações & 0,9668 \\
\hline Ciência & 0,9369 & Total & 0,9466 \\
\hline Pensamento crítico & 0,9788 & Variáveis de spillover de conhecimento & MSA \\
\hline Aprendizado ativo & 0,9775 & Compreensão oral & 0,9579 \\
\hline Solução de problemas complexos & 0,9773 & Compreensão escrita & 0,9568 \\
\hline Análise operacional & 0,9505 & Expressão oral & 0,962 \\
\hline Design de tecnologia & 0,9373 & Expressão escrita & 0,9531 \\
\hline Transporte & 0,7204 & Compreender um discurso & 0,9617 \\
\hline Administração e gerência & 0,9452 & Falar com clareza & 0,9537 \\
\hline Clerical & 0,9147 & Socializar & 0,9395 \\
\hline Economia e contabilidade & 0,939 & Cooperativo & 0,9489 \\
\hline Vendas e marketing & 0,8999 & Trabalhar em cooperação & 0,9547 \\
\hline Serviço ao cliente & 0,9411 & Compreensão de leitura & 0,9612 \\
\hline Recursos humanos & 0,9508 & Audição ativa & 0,9693 \\
\hline Produção e processamento & 0,793 & Escrever & 0,959 \\
\hline
\end{tabular}




\section{TABELA 1}

Habilidades dos trabalhadores relacionadas à inovação e aos testes estatísticos para aplicação da ACP

\begin{tabular}{|c|c|c|c|}
\hline Produção de alimentos & 0,5965 & Falar & 0,9646 \\
\hline Computação e eletrônica & 0,9527 & Aprender estrategicamente & 0,9433 \\
\hline Engenharia e tecnologia & 0,8975 & Instruir & 0,9485 \\
\hline Design & 0,8533 & $\begin{array}{l}\text { Interpretar o sentido de informaçóes } \\
\text { para outros }\end{array}$ & 0,9717 \\
\hline Construção & 0,7769 & $\begin{array}{l}\text { Comunicar-se com superiores, } \\
\text { colaboradores e subordinados }\end{array}$ & 0,9794 \\
\hline Mecânica & 0,8555 & $\begin{array}{l}\text { Comunicar-se com pessoas fora da } \\
\text { organização }\end{array}$ & 0,9563 \\
\hline Matemática & 0,9409 & $\begin{array}{l}\text { Estabelecer e manter relações } \\
\text { interpessoais }\end{array}$ & 0,9583 \\
\hline Física & 0,9059 & $\begin{array}{l}\text { Coordenar o trabalho e as atividades de } \\
\text { outros }\end{array}$ & 0,9294 \\
\hline Química & 0,8976 & Desenvolver e construir times & 0,9303 \\
\hline Biologia & 0,9131 & Treinar e ensinar outros & 0,92 \\
\hline Psicologia & 0,9416 & Treinar e desenvolver outros & 0,9353 \\
\hline Sociologia e antropologia & 0,9471 & Frequência de discussões face-a-face & 0,9542 \\
\hline Geografia & 0,8655 & Frequência de contatos com outros & 0,9654 \\
\hline Medicina e odontologia & 0,9067 & $\begin{array}{l}\text { Trabalhar com grupo de trabalho ou } \\
\text { times }\end{array}$ & 0,9282 \\
\hline Terapia e aconselhamento & 0,9274 & Total & 0,9542 \\
\hline Educação e treinamento & 0,9426 & & \\
\hline \multicolumn{4}{|c|}{ Teste de esfericidade de Bartlett } \\
\hline \multicolumn{2}{|c|}{ Potencial inovativo } & \multicolumn{2}{|l|}{ Spillover de Conhecimento } \\
\hline Chi-quadrado & 227000 & Chi-quadrado & 118000 \\
\hline Graus de liberdade & 1830 & Graus de liberdade & 325 \\
\hline P-valor & 0,000 & P-valor & 0,000 \\
\hline
\end{tabular}

Fonte: Onet Cálculos dos autores. 
TABELA 2

ACP das variáveis selecionadas da Onet

\begin{tabular}{|c|c|c|c|c|c|c|c|}
\hline Componentes & Autovalor & $\begin{array}{c}\text { Variância } \\
(\%)\end{array}$ & \begin{tabular}{|l|} 
Acumulado da \\
variância (\%)
\end{tabular} & & & & \\
\hline \multicolumn{8}{|c|}{ Potencial Inovativo } \\
\hline$\overline{\text { Comp1 }}$ & 24,8521 & 0,4074 & 0,4074 & Comp45 & 0,0885 & 0,0015 & 0,9862 \\
\hline Comp2 & 6,7577 & 0,1108 & 0,5182 & Comp46 & 0,0841 & 0,0014 & 0,9875 \\
\hline Comp3 & 4,2032 & 0,0689 & 0,5871 & Comp47 & 0,0769 & 0,0013 & 0,9888 \\
\hline Comp4 & 3,1816 & 0,0522 & 0,6393 & Comp48 & 0,0745 & 0,0012 & 0,9900 \\
\hline Comp5 & 2,7189 & 0,0446 & 0,6838 & Comp49 & 0,0698 & 0,0011 & 0,9912 \\
\hline Comp6 & 2,1756 & 0,0357 & 0,7195 & Comp 50 & 0,0677 & 0,0011 & 0,9923 \\
\hline Comp7 & 1,7525 & 0,0287 & 0,7482 & Comp51 & 0,0610 & 0,0010 & 0,9933 \\
\hline Comp8 & 1,4146 & 0,0232 & 0,7714 & Comp52 & 0,0592 & 0,0010 & 0,9942 \\
\hline Comp9 & 1,1757 & 0,0193 & 0,7907 & Comp53 & 0,0539 & 0,0009 & 0,9951 \\
\hline Comp10 & 1,0119 & 0,0166 & 0,8073 & Comp 54 & 0,0521 & 0,0009 & 0,9960 \\
\hline Comp11 & 0,9218 & 0,0151 & 0,8224 & Comp55 & 0,0478 & 0,0008 & 0,9968 \\
\hline Comp12 & 0,7867 & 0,0129 & 0,8353 & Comp56 & 0,0452 & 0,0007 & 0,9975 \\
\hline Comp13 & 0,6993 & 0,0115 & 0,8467 & Comp57 & 0,0399 & 0,0007 & 0,9982 \\
\hline Comp14 & 0,6937 & 0,0114 & 0,8581 & Comp58 & 0,0370 & 0,0006 & 0,9988 \\
\hline Comp15 & 0,6086 & 0,0100 & 0,8681 & Comp59 & 0,0328 & 0,0005 & 0,9993 \\
\hline Comp16 & 0,5772 & 0,0095 & 0,8776 & Comp60 & 0,0277 & 0,0005 & 0,9998 \\
\hline Comp17 & 0,5320 & 0,0087 & 0,8863 & Comp61 & 0,0146 & 0,0002 & 1,0000 \\
\hline Comp18 & 0,5068 & 0,0083 & 0,8946 & \multicolumn{4}{|c|}{ Spillover de Conhecimento } \\
\hline Comp19 & 0,4562 & 0,0075 & 0,9021 & Comp1 & 17,0418 & 0,6555 & 0,6555 \\
\hline Comp20 & 0,3975 & 0,0065 & 0,9086 & Comp2 & 2,0284 & 0,0780 & 0,7335 \\
\hline Comp21 & 0,3905 & 0,0064 & 0,9150 & Comp3 & 1,7005 & 0,0654 & 0,7989 \\
\hline Comp22 & 0,3441 & 0,0056 & 0,9206 & Comp4 & 1,2825 & 0,0493 & 0,8482 \\
\hline Comp23 & 0,3142 & 0,0052 & 0,9258 & Comp5 & 0,8199 & 0,0315 & 0,8797 \\
\hline Comp 24 & 0,2900 & 0,0048 & 0,9305 & Comp6 & 0,4389 & 0,0169 & 0,8966 \\
\hline Comp25 & 0,2752 & 0,0045 & 0,9350 & Comp7 & 0,4024 & 0,0155 & 0,9121 \\
\hline Comp26 & 0,2525 & 0,0041 & 0,9392 & Comp8 & 0,3423 & 0,0132 & 0,9253 \\
\hline Comp27 & 0,2380 & 0,0039 & 0,9431 & Comp9 & 0,2828 & 0,0109 & 0,9361 \\
\hline Comp28 & 0,2211 & 0,0036 & 0,9467 & Comp10 & 0,2595 & 0,0100 & 0,9461 \\
\hline Comp29 & 0,2138 & 0,0035 & 0,9502 & Comp11 & 0,2211 & 0,0085 & 0,9546 \\
\hline Comp30 & 0,2057 & 0,0034 & 0,9536 & Comp12 & 0,1843 & 0,0071 & 0,9617 \\
\hline Comp31 & 0,1955 & 0,0032 & & Comp13 & 0,1522 & 0,0059 & 0,9676 \\
\hline Comp32 & 0,1832 & 0,0030 & 0,9598 & Comp14 & 0,1428 & 0,0055 & 0,9731 \\
\hline Comp33 & 0,1666 & 0,0027 & 0,9625 & Comp15 & 0,1266 & 0,0049 & 0,9779 \\
\hline Comp34 & 0,1626 & 0,0027 & 0,9652 & Comp16 & 0,1172 & 0,0045 & 0,9824 \\
\hline Comp35 & 0,1567 & 0,0026 & 0,9678 & Comp17 & 0,0956 & 0,0037 & 0,9861 \\
\hline Comp36 & 0,1404 & 0,0023 & 0,9701 & Comp18 & 0,0769 & 0,0030 & 0,9891 \\
\hline Comp37 & 0,1272 & 0,0021 & 0,9721 & Comp19 & 0,0643 & 0,0025 & 0,9915 \\
\hline Comp38 & 0,1242 & 0,0020 & 0,9742 & Comp20 & 0,0525 & 0,0020 & 0,9936 \\
\hline Comp39 & 0,1198 & 0,0020 & 0,9761 & Comp21 & 0,0471 & 0,0018 & 0,9954 \\
\hline Comp40 & 0,1147 & 0,0019 & 0,9780 & Comp22 & 0,0429 & 0,0016 & 0,9970 \\
\hline Comp41 & 0,1105 & 0,0018 & 0,9798 & Comp23 & 0,0241 & 0,0009 & 0,9979 \\
\hline Comp42 & 0,1033 & 0,0017 & 0,9815 & Comp24 & 0,0207 & 0,0008 & 0,9987 \\
\hline Comp43 & 0,1016 & 0,0017 & 0,9832 & Comp25 & 0,0185 & 0,0007 & 0,9994 \\
\hline Comp44 & 0,0925 & 0,0015 & 0,9847 & Comp26 & 0,0145 & 0,0006 & 1,0000 \\
\hline
\end{tabular}

Fonte: Onet Cálculos dos autores. 
TABELA 3

Rotação Varimax dos dez componentes selecionados de potencial inovativo

\begin{tabular}{l|c|c|c}
\hline Componentes & Autovalor & $\begin{array}{c}\text { Variância } \\
(\mathbf{\%})\end{array}$ & $\begin{array}{c}\text { Acumulado da } \\
\text { variância (\%) }\end{array}$ \\
\hline Comp1 & 14,3697 & 0,2356 & 0,2356 \\
Comp2 & 6,46071 & 0,1059 & 0,3415 \\
Comp3 & 4,88438 & 0,0801 & 0,4216 \\
Comp4 & 4,68681 & 0,0768 & 0,4984 \\
Comp5 & 4,659 & 0,0764 & 0,5748 \\
Comp6 & 4,65563 & 0,0763 & 0,6511 \\
Comp7 & 2,67718 & 0,0439 & 0,695 \\
Comp8 & 2,59899 & 0,0426 & 0,7376 \\
Comp9 & 2,34602 & 0,0385 & 0,776 \\
Comp10 & 1,90529 & 0,0312 & 0,8073 \\
\hline
\end{tabular}

Fonte: Onet Cálculos dos autores.

TABELA 4

Rotação Varimax dos quatro componentes selecionados de spillover de conhecimento

\begin{tabular}{l|c|c|c}
\hline \multicolumn{1}{c|}{ Componentes } & Autovalor & $\begin{array}{c}\text { Variância } \\
(\%)\end{array}$ & $\begin{array}{c}\text { Acumulado da } \\
\text { variância (\%) }\end{array}$ \\
\hline Comp1 & 12,079 & 0,4646 & 0,4646 \\
Comp2 & 3,56572 & 0,1371 & 0,6017 \\
Comp3 & 3,2411 & 0,1247 & 0,7264 \\
Comp4 & 3,1674 & 0,1218 & 0,8482 \\
\hline
\end{tabular}

Fonte: Onet Cálculos dos autores.

TABELA 5

Estatísticas descritivas das notas das ocupações brasileiras

\begin{tabular}{|c|c|c|c|c|}
\hline & Média & Desvio-padrão & Máximo & Mínimo \\
\hline \multicolumn{5}{|l|}{ Potencial Inovativo } \\
\hline $\begin{array}{l}\text { Capacidade de utilizar e gerar conhecimentos e } \\
\text { de solucionar problemas }\end{array}$ & 0,0242 & 3,8006 & 13,2948 & $-8,4626$ \\
\hline $\begin{array}{l}\text { Capacidade de analisar e de processar dados, } \\
\text { informaçóes e novos conhecimentos }\end{array}$ & 0,0004 & 2,5455 & 7,9110 & $-8,0822$ \\
\hline $\begin{array}{l}\text { Ciências sociais e capacidade de administrar e } \\
\text { gerenciar }\end{array}$ & 0,0069 & 2,2077 & 7,1978 & $-4,3582$ \\
\hline Ciências humanas e línguas & 0,0131 & 2,1740 & 13,7128 & $-3,0694$ \\
\hline Ciências da saúde & 0,0169 & 2,1683 & 8,1459 & $-3,3214$ \\
\hline Engenharia e design & $-0,0003$ & 2,1614 & 7,2307 & $-4,0973$ \\
\hline Comunicação e pensamento criativo & 0,0179 & 1,6448 & 9,7459 & $-3,2390$ \\
\hline Transporte, construção e segurança pública & $-0,0034$ & 1,6157 & 7,2076 & $-3,2944$ \\
\hline Tecnologia da informação e comunicação (ICT) & 0,0027 & 1,5301 & 6,4325 & $-2,6090$ \\
\hline Ciências naturais & $-0,0006$ & 1,3817 & 8,4068 & $-2,2927$ \\
\hline \multicolumn{5}{|l|}{ Spillover de conhecimento } \\
\hline Capacidade de expressão e compreensão & 0,0139 & 3,4842 & 8,3198 & $-7,8315$ \\
\hline Capacidade de treinar, ensinar e instruir & 0,0120 & 1,8927 & 6,0205 & $-4,3236$ \\
\hline Capacidade de socializar e cooperar & 0,0094 & 1,8069 & 5,2616 & $-3,5005$ \\
\hline $\begin{array}{l}\text { Capacidade de desenvolver e trabalhar em grupo } \\
\text { e de interagir }\end{array}$ & $-0,0079$ & 1,7754 & 4,5780 & $-6,4824$ \\
\hline
\end{tabular}

Fonte: Rais 2012 e Onet. Cálculos dos autores. 
TABELA 6

Ipir para diferentes níveis geográficos

2003

\begin{tabular}{|c|c|c|c|}
\hline Regióes & Ipir & $\begin{array}{l}\text { Potencial } \\
\text { inovativo }\end{array}$ & $\begin{array}{c}\text { Spillover de } \\
\text { conhecimento }\end{array}$ \\
\hline Brasil & 0,437 & 0,443 & 0,421 \\
\hline Sudeste & 0,507 & 0,514 & 0,490 \\
\hline Norte & 0,470 & 0,475 & 0,460 \\
\hline Sul & 0,396 & 0,404 & 0,378 \\
\hline Nordeste & 0,281 & 0,286 & 0,269 \\
\hline Centro-Oeste & 0,258 & 0,262 & 0,249 \\
\hline AM & 0,869 & 0,875 & 0,854 \\
\hline SP & 0,554 & 0,562 & 0,536 \\
\hline RJ & 0,497 & 0,503 & 0,485 \\
\hline RS & 0,432 & 0,441 & 0,409 \\
\hline BA & 0,391 & 0,396 & 0,378 \\
\hline PA & 0,382 & 0,388 & 0,367 \\
\hline MG & 0,382 & 0,388 & 0,367 \\
\hline SC & 0,364 & 0,371 & 0,347 \\
\hline $\mathrm{AP}$ & 0,350 & 0,355 & 0,337 \\
\hline ES & 0,311 & 0,317 & 0,297 \\
\hline DF & 0,309 & 0,310 & 0,306 \\
\hline MA & 0,296 & 0,301 & 0,286 \\
\hline GO & 0,287 & 0,291 & 0,277 \\
\hline PE & 0,286 & 0,290 & 0,276 \\
\hline SE & 0,284 & 0,288 & 0,275 \\
\hline PI & 0,284 & 0,288 & 0,272 \\
\hline $\mathrm{CE}$ & 0,256 & 0,261 & 0,241 \\
\hline $\mathrm{RN}$ & 0,255 & 0,259 & 0,245 \\
\hline $\mathrm{PB}$ & 0,243 & 0,248 & 0,232 \\
\hline TO & 0,238 & 0,241 & 0,229 \\
\hline PA & 0,228 & 0,232 & 0,220 \\
\hline MS & 0,222 & 0,226 & 0,213 \\
\hline $\mathrm{AC}$ & 0,218 & 0,221 & 0,213 \\
\hline MT & 0,214 & 0,217 & 0,205 \\
\hline RO & 0,213 & 0,215 & 0,205 \\
\hline $\mathrm{RR}$ & 0,208 & 0,210 & 0,202 \\
\hline $\mathrm{AL}$ & 0,178 & 0,183 & 0,167 \\
\hline
\end{tabular}

Fonte: Rais 2003, Pintec 2000 e Onet Cálculos dos autores. 
TABELA 7

Modelo Anova do IHab

\begin{tabular}{|c|c|c|c|c|c|c|}
\hline$H a b_{m, s, a}$ & Coeficientes & Desvios-padrão & $\mathbf{t}$ & $P>|t|$ & \multicolumn{2}{|c|}{$\begin{array}{c}\text { [95\% - Intervalo } \\
\text { de Confiança }]\end{array}$} \\
\hline Intercepto & $-1,3013$ & 0,0058 & $-223,37$ & 0,00 & $-1,3127$ & $-1,2898$ \\
\hline Setor $A$ & 0,4352 & 0,0107 & 40,67 & 0,00 & 0,4142 & 0,4562 \\
\hline Setor $M A$ & 0,1796 & 0,0095 & 18,89 & 0,00 & 0,1609 & 0,1982 \\
\hline Setor $M B$ & 0,0811 & 0,0083 & 9,82 & 0,00 & 0,0649 & 0,0973 \\
\hline$P \& D$ & 2,2214 & 0,0196 & 113,46 & 0,00 & 2,1830 & 2,2597 \\
\hline$($ Setor $A * P \& D)$ & $-0,2760$ & 0,0325 & $-8,49$ & 0,00 & $-0,3397$ & $-0,2123$ \\
\hline$($ Setor $M A * P \& D)$ & $-0,1198$ & 0,0316 & $-3,79$ & 0,00 & $-0,1817$ & $-0,0579$ \\
\hline$($ Setor $M B * P \& D)$ & $-0,0612$ & 0,0297 & $-2,06$ & 0,04 & $-0,1195$ & $-0,0029$ \\
\hline N. de observações & 16549 & \multirow{2}{*}{\multicolumn{5}{|c|}{ Teste de heterocedasticidade de Breusch-Pagan/Cook-Weisberg }} \\
\hline $\mathrm{F}(7,16541)$ & 5359,1 & & & & & \\
\hline Prob $>$ F & 0,0000 & \multicolumn{5}{|c|}{ Ho: Variância constante } \\
\hline $\mathrm{R} 2$ & 0,6940 & Chi2(1) & 777,25 & & & \\
\hline R2 ajustado & 0,6939 & Prob $>$ Chi2 & 0,0000 & & & \\
\hline
\end{tabular}

Fonte: RAIS 2012, Pintec 2000 e Onet Cálculos dos autores. 